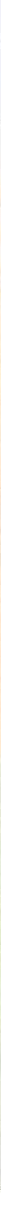

\title{
A MODEL FOR WOMEN-LED
}

VALUE CHAINS IN MARKET

SYSTEM DEVELOPMENT IN

FRAGILE CONTEXTS

Program Learning Case Studies from the Occupied Palestinian Territory 


\section{OXFAM CASE STUDY - NOVEMBER 2019}

Economic empowerment for women is a key component of Oxfam's Economic Justice programme in the Occupied Palestinian Territory and Israel (OPTI). The snake cucumber (faqous) value chain provides a good example of an intervention that focuses on women's economic empowerment (WEE). This value chain is unique in its nature and scope as it is led by women. This case study examines the factors that have contributed to increasing women's access to and control over economic opportunities and identifies learning and best practice to be used as a model for future interventions.

(C) Oxfam International November 2019

This case study was written by Nabila El-Ahmed. Oxfam acknowledges the assistance of the Economic and Social Development Center of Palestine (ESDC) in its production. It is part of a series of papers written to inform public debate on development and humanitarian policy issues.

For further information on the issues raised in this paper please email mohammed.sawafta@oxfam.org.

This publication is copyright but the text may be used free of charge for the purposes of advocacy, campaigning, education, and research, provided that the source is acknowledged in full. The copyright holder requests that all such use be registered with them for impact assessment purposes. For copying in any other circumstances, or for re-use in other publications, or for translation or adaptation, permission must be secured and a fee may be charged. E-mail policyandpractice@oxfam.org.uk.

The information in this publication is correct at the time of going to press.

Published by Oxfam GB for Oxfam International under ISBN 978-1-78748-533-4 in November 2019.

DOI:10.21201/2019.5334

Oxfam GB, Oxfam House, John Smith Drive, Cowley, Oxford, OX4 2JY, UK.

Cover photo: A woman farmer collecting snake cucumber. Suhaib Jarrar/Oxfam in OPTI 2019 


\section{SUMMARY}

Economic empowerment for women is a key component of Oxfam's Economic Justice programme in the Occupied Palestinian Territory and Israel (OPTI). The snake cucumber (faqous) value chain provides a good example of an intervention that focuses on women's economic empowerment (WEE). This value chain is unique in its nature and scope as it is led by women. This case study examines the factors that have contributed to increasing women's access to and control over economic opportunities and identifies learning and best practice to be used as a model for future interventions.

Strategic interventions - such as demonstration sites showcasing a diversification of crop varieties, crop spacing, identifying and addressing fungal diseases and the use of greenhouses and field tunnels - can be highly successful in a gendered market system. This project shows that such interventions can lead to changes in behaviour and attitudes that can empower the women involved, an increase in income due to better understanding of agricultural techniques, especially in identifying and treating diseases, and an increased appetite for adopting new techniques and investing in their livelihoods. The women have developed new business acumen that has enabled them to negotiate collectively for better prices, to an extent that has been noticed by the Palestinian Authority Ministry of Agriculture (MoA), which is now offering them longterm support.

The project has proved that well planned, long-term support to identified gendered markets can be an effective modality for WEE. Key lessons have included the importance of finding entry points into the market system, such as cooperatives, identifying and investing in existing leadership capacities, creating enabling environments by engaging community members and their leaders to address systemic barriers, incentivizing participation, analysing potential negative impacts and offering long-term support and investment to ensure buy-in from women.

This women-led value chain provides an interesting case study for identifying models and best practices to promote similar interventions. Oxfam believes that effective WEE is realized when women have control and are benefiting from resources, assets, income and time savings. ${ }^{1}$ Achieving meaningful economic empowerment requires transformative and systemic change across a number of domains, including decision making, control over assets, the ability to maintain a living wage, active participation in enterprise, living free from violence and systemic change across social, economic and political systems. ${ }^{2}$ To that end, this is a fitting case study that allows for learning and potential scale-up. 


\section{INTRODUCTION}

The snake cucumber (faqous) value chain is part of Oxfam's interventions within the project 'Developing equitable agricultural production and market systems for resilient economic development in the Occupied Palestinian Territory'. ${ }^{3}$ This women-led value chain and the presence of a well-organized and emerging women's cooperative provided an opportunity to invest in strengthening women's agricultural capacities in order to improve their access to markets and enable them to become agents for social change. These unique characteristics, combined with the positive immediate outcomes of the intervention, make for a useful case study.

Oxfam works within a rights-based approach that prioritizes women's economic empowerment (WEE) and puts women at the heart of all that it does. This case study has the potential to contribute towards efforts to improve the integration of women-led value chains within a market systems development (MSD) approach. An approach of this kind aims to bring about systemic change, foster equitable access to markets and stimulate income and employment opportunities to improve the lives of people living in poverty.

The case study examines specific aspects of the intervention's implementation and outcomes to identify the factors contributing to success, the gaps and lessons learned. The objective is to learn from these lessons in order to strengthen future interventions and ensure effective and equitable integration of women in future MSD approaches.

\section{CONTEXT}

The village of Deir Ballut is located in the north of the West Bank in the Governorate of Salfit. Nearly all the village land (94.8\%) is designated as Area $\mathrm{C}$, which means that it is under the complete military and civil control of Israel, as part of the overall occupation of the OPT. ${ }^{4}$ This has considerable implications for the freedom of movement and security of residents. Israeli-imposed restrictions have severe impacts on agriculture in the village, particularly as so much of its agricultural land is in Area C. Most household livelihoods in Deir Ballut are dependent on agriculture to some degree. Consequently, Israeli control over access to agricultural land and natural resources such as wells and aquifers, along with land confiscations and demolition of buildings, has a significant bearing on villagers' livelihoods and well-being. Limited access to water is highly problematic and places significant strain on agricultural production. This disproportionately affects women, who in large part bear responsibility for household tasks.

Farmers in Deir Ballut have been cultivating faqous for decades, following conventional rain-fed farming practices. Over time, however, the scar-city of water, a lack of diversification in seed varieties and farming meth-ods, the spread of plant diseases and a lack of technical expertise have contributed to increasingly poor crop quality and quantity. 
Women in Deir Ballut have historically been very active in the agricultural sector; however, they continue to face multiple challenges that are compounded by the occupation and by patriarchal social norms. These include travel restrictions, check-point closures and security threats from neighbouring Israeli settlements, which present major challenges and severely affect women's freedom of movement, safety and livelihoods. The intersecting factors of occupation, gender and agricultural degradation contribute to economic fragility, with limited opportunities for growth and development.

\section{THE COOPERATIVE}

Established in 2016, the Deir Ballut Women's Cooperative provides opportunities for local women to develop new skills and earn an income. With a sound organizational and administrative framework, a strong leader in its founder, Amneh Khader, and committed and active members, the cooperative has successfully operated a small chicken farm, processed and sold maftoul (Palestinian couscous), produced and sold pickled faqous and over the past year cultivated and sold faqous. The cooperative has also organized an annual faqous festival for the past two years, which has been attended by regional- and national-level government ministers, local NGOs and residents of neighbouring villages. During this year's festival 12 tonnes of faqous was sold, with an estimated value of $€ 16,000$. The women's cooperative also plays an active role in the community and the village municipality.

Um Ismail, a cooperative member, noted that transparency and participatory decision making differentiate this cooperative from the others she has worked with previously. She said: 'Women did not have a voice in decision making, but here we all collectively make decisions together.'

Despite their success and potential, the cooperative's president, Amneh Khader, explained that they still have a long road ahead of them. In particular, she hopes that more external organizations and governmental bodies will make more concerted efforts to ensure the cooperative's meaningful participation and inclusion in future initiatives.

\section{WOMEN AND FARMING IN DEIR}

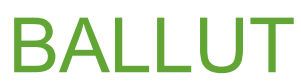

In Deir Ballut, cultivating, pickling and selling faqous is the domain of women farmers. This is uncommon to the village; it is not completely clear how it came to be, but coop members explained that it has long been part of the culture and fabric of the village for women to participate in agriculture, and since the occupation began women have taken on an ever larger role as economic factors have pulled the men of the village to work inside Israel. 


\section{THE INTERVENTION}

The intervention is grounded in an MSD approach to strengthen the capacities of local women farmers and to stimulate faltering crop outputs and improve livelihoods. Oxfam and its partner, the Economic and Social Development Center of Palestine (ESDC), developed this strategy to engage women farmers, to develop their agricultural and marketing capacities and to facilitate their access to wider markets. The intervention includes three main components: provision of extension and guidance services, installation of demonstration sites and facilitating access to new markets.

\section{Demonstration sites}

A private sector agriculture company, El-Jinidi, was contracted to administer five demonstration sites to apply and model a variety of technical approaches to the cultivation of faqous for the purpose of learning and replication. The five demo sites included a greenhouse, field tunnels, conventional farming (for comparison), mulch and supplementary irrigation. Five women members of the cooperative were chosen to host the demo sites on their land. These sites enabled farmers in the community to observe at first hand new agricultural techniques and practices in their own context and environment and assess their viability and effectiveness.

In coordination with the Ministry of Agriculture (MoA), ESDC procured the services of an agronomist from El-Jinidi, who provided direction and close monitoring throughout the process. Each demo site focused on a specific approach to provide wide-ranging opportunities to experiment with new techniques and to learn.

\section{Extension services}

The demo sites were augmented by extension services to provide a unique experiential learning opportunity for the women farmers of Deir Ballut. The El-Jinidi agronomist also provided ongoing extension services pre- and post-planting. These services ranged from information sessions on sound agricultural practices such as proper germination, fertilization and irrigation to guidance during the season to tackle diseases that had damaged crops in previous seasons. A total of 35 extension visits were delivered to 210 beneficiaries over a period of four months.

ESDC field staff and two women engineers from the MoA also participated in the extension service sessions. This training strengthened the capacity of ESDC and the MoA to provide additional monitoring field visits throughout the planting and harvesting seasons. Based on the success of this project, ESDC and MoA are currently in talks to adapt and adopt this approach in other villages. 


\section{Facilitating access to markets}

A number of factors hamper women's access to wider markets, including patriarchal social norms, transportation expenses and restrictions, and a lack of networks and access to markets. Prior to the intervention, the majority of women farmers in Deir Ballut sold their products to passers-by at the side of the road. This ad hoc way of marketing requires women to sit outside in the sun for long hours at a time in difficult conditions and is subject to chance flows of traffic. Alternatively, women farmers sold to two market traders who however exercised a monopoly over their produce, often at less than the market price. To improve access to new markets and networks, Oxfam and ESDC facilitated a relationship between the women's cooperative and Hamza Ballut, the produce manager at Bravo, the largest supermarket chain in Ramallah.

Mr. Ballut explained that he was motivated by both business and social justice. From a business standpoint, there is market demand for faqous, and supporting the women's cooperative was an added incentive. He commented: 'As traders, we are proud to set an example by working directly with farmers ... By doing this we are supporting farmers and protecting them from market forces ... and delivering a quality product to our customers at a good price.'

To further support the cooperative's capacity to participate in broader markets, ESDC helped to update the cooperative's packing capacity by providing a packing unit to sort and pack faqous in labelled packages.

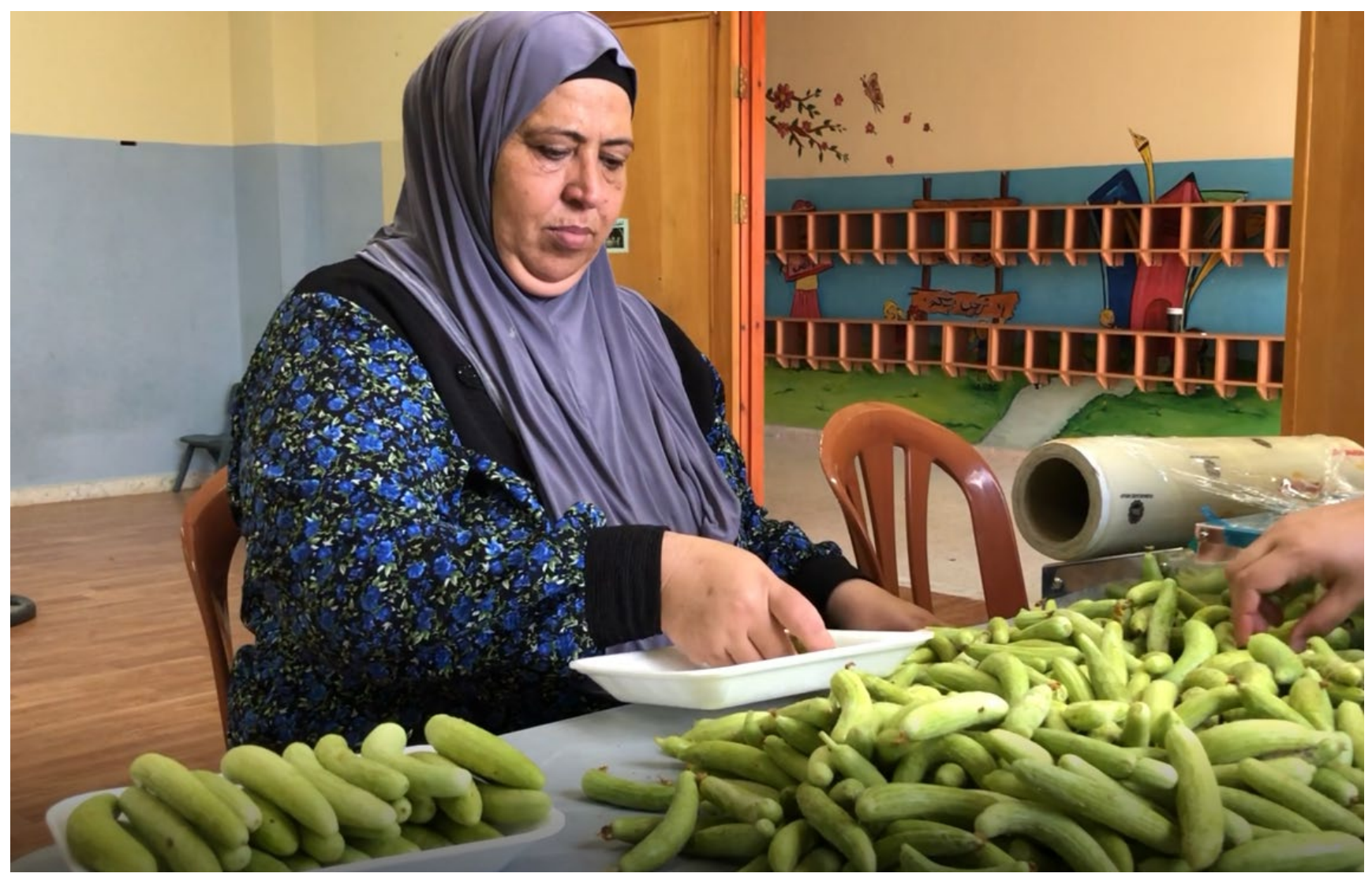

A woman in a cooperative packaging cucumbers to be sold to Bravo supermarket. Suhaib Jarrar/Oxfam in OPTI 2019. 


\section{Fencing and latrines}

The proliferation of wild pigs in the region poses a major physical threat to the local population. Farmers who spend long hours in open fields are especially vulnerable. The pigs also damage and uproot crops. Oxfam has fenced over 102 dunums ${ }^{5}$ (13 of which use solar-powered electric fencing) as part of its multi-intervention approach and risk mitigation strategy.

Previously, women had to go back and forth to their homes to use the toilet. As a mitigation measure, two latrines have been installed in the fields. This has served to improve working conditions and lessen the time burden of working outdoors.

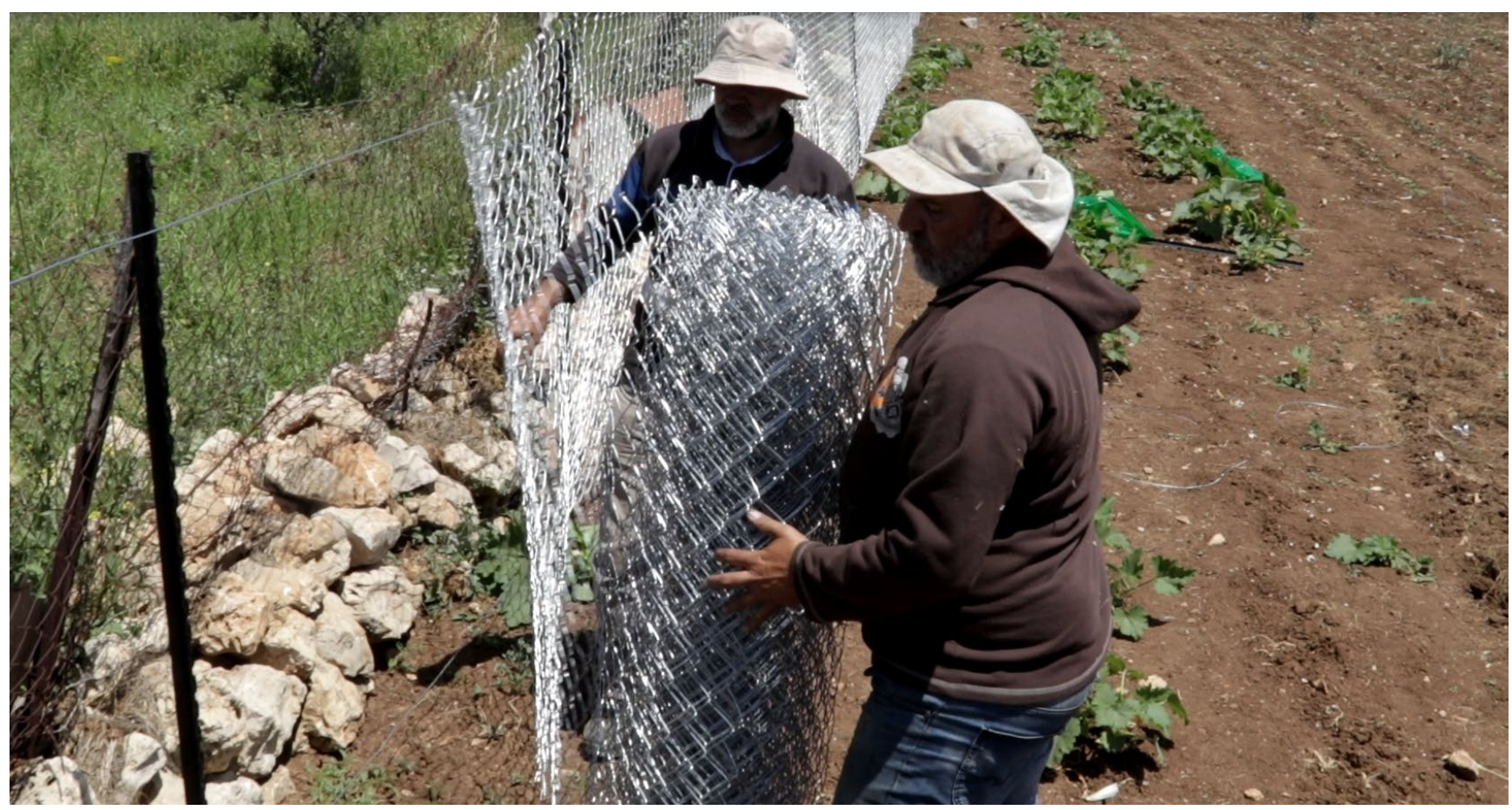

Workers fencing new land in Der Ballout to be planted with snake cucumber. Suhaib Jarrar/Oxfam in OPTI 2019.

\section{RESULTS}

Results have been observed in a number of areas, including knowledge, attitudes, income and behaviour. Women have reported a change in their attitudes and improvements in their knowledge of agricultural techniques and their farming capacity. Their acceptance and adoption of new and diverse farming techniques has contributed to significant improvements in crop yields and quality, ultimately increasing the income of participating women farmers.

\section{Increase in knowledge and changes in attitude}

Extension services and demonstration sites have enabled the women farmers to accept and adopt new agricultural practices that have 
improved the quality and quantity of their output. Newly introduced techniques include the diversification of crop varieties, crop spacing, identifying and addressing fungal growth and the use of greenhouses and field tunnels. With the knowledge gained and the implementation of diverse techniques have come tangible improvements in crop quality and yield. This has contributed to self-reported changes in attitudes relating to new agricultural practices. For example, before the intervention, most women farmers were suspicious of and reluctant to adopt any new practice that deviated from their established ways of farming.

\section{Improved income}

Guidance provided on the early detection of white powdery mildew, a common fungal disease that affects faqous, and the provision of training on treatment methods such as the proper and safe use of fungicides have helped to improve yields and hence farmers' incomes. This disease had affected the crop in Deir Ballut for the previous two years, significantly affecting both its quality and its quantity. However, this year early detection and treatment had a dramatic impact on output. The 2017 crop amounted to $49,5068 \mathrm{~kg}$ and in 2018 it was $33,7776 \mathrm{~kg}$ (this decline was a result of the mildew), but in 2019 it rose to $57,4633 \mathrm{~kg}$.

\section{Behavioural change}

In addition to improvements in crop yield and quality, there were changes in women's attitudes and behaviour. Initially, women farmers were sceptical about unfamiliar practices and unwilling to adopt them. However, when the demo sites began to yield positive results, most of the women adopted the new practices and asked for support to treat their crops. The president of the cooperative, Amneh Khader, noted the importance of the demo sites: 'This was the first time that we received practical and applied training. This made a real difference.'

Acceptance was widespread, to an extent that required a response from ESDC to provide fungicide to treat all the crop, which it had not planned for. To date, two women have also reported independently treating their crops late in the season. Through the coordination of Oxfam and ESDC, the MoA was engaged and participated in demo sites and extension services. This has led to a more consistent presence of the MoA and stronger ties with the community.

In previous years the bulk of the village's output was sold to two market traders, who monopolized the market. However, the extension services helped increase women farmers' confidence to participate in the market themselves. They had previously sold their faqous to the traders at low prices, compared with the market price, but this season they reported that better knowledge of market prices had given them the confidence to negotiate a competitive price.

The link that was facilitated with Bravo enabled women members of the cooperative to develop new marketing skills and acumen, to sort and package a product based on set standards and to meet buyer demands. 
They reported selling $1,500 \mathrm{~kg}$ of faqous to Bravo over a period of two months at a competitive market price of NIS8/kg compared with $4 \mathrm{NIS} / \mathrm{kg}$ in previous years to market traders. The cooperative also negotiated a set price and a contract with the supermarket produce manager; based on the success of this trial, he has also inquired about purchasing garlic from the cooperative in future.

Overall, the intervention has contributed to strengthening the existing capacity of women leaders by increasing their skills and knowledge and expanding their networks. Their role as community leaders has proved to be beneficial and is a noteworthy variable that can contribute to sustainability and further growth and replication. As Amneh stated: 'We didn't want this [the intervention] to only benefit the cooperative, but the women of the village as well.'

A video documenting this case study is available here.

\section{WHAT WE LEARNED}

Two key variables need to be highlighted in this case: the predominance of women active in the value chain and the presence of an active and well organized women's cooperative. The women's initiative was a key factor in the success of this intervention and is vital for its sustainability and further growth. However, support services are still necessary to further strengthen and develop women's capacity to gain access to and control over resources. The following are some of the lessons learned that can inform the development of future interventions to better serve this end.

- Experiential learning is critical to changing attitudes. The demo sites were very effective as both a learning tool and as a means of shifting attitudes towards long-held farming practices.

- Targeting extension services towards women can pay substantial dividends, especially as such services traditionally target only men. This intervention is a case in point where the participation of women at all stages proved to be effective and beneficial.

- Non-technical support services (the provision of fencing and latrines in this case) are important elements that address practical needs and barriers, and serve to improve working conditions and women's ability to access livelihoods.

- Identifying key actors in the community to pilot the intervention and influence others was essential in the initial stages. The participation of the Deir Ballut Women's Cooperative was a key entry point into the community, and it helped to overcome barriers and engage a larger number of women.

- Meaningful engagement of women in leadership roles (as demonstrated by the role taken by the women's cooperative) can lead to numerous positive outcomes. Opening up spaces and opportunities for women to take the lead and mobilize others is ultimately more effective and rewarding for the women involved and for the community as a whole. 
- Women-led interventions are important drivers of women's economic empowerment. Change at the individual level (for both men and women) and improving women's access to economic opportunities and resources are critical components in a transformative approach towards women's economic empowerment.

\section{RECOMMENDATIONS}

The following areas need to be considered and further refined to develop more responsive interventions that engage women in meaningful and effective ways. This case study has allowed Oxfam to explore entry points and areas of strength and to identify gaps where further development is needed. Moving forward, this can be used as a model to replicate and scale up similar interventions.

- Identify and invest in existing leadership capacities of local women through targeted participatory activities.

- Create enabling environments by engaging community members and their leaders to address systemic barriers: for example, by directly engaging local women's groups in developing interventions. In this case, cooperative members also served as role models and mobilized other women in the community to participate in the extension services provided through the intervention.

- Incentivize the participation and engagement of youth through targeted initiatives by facilitating their access and participation in viable economic opportunities.

- Anticipate some degree of backlash and mitigate for it when challenging existing power structures by being inclusive and responsive to community needs.

- Identify constraints or potential harms by carrying out exercises such as Oxfam's Rapid Care Analysis ${ }^{6}$ and time use surveys to identify how women's responsibility for care affects their participation in interventions. 
1 Oxfam (2017). Oxfam's Conceptual Framework on Women's Economic Empowerment. https://policypractice.oxfam.org.uk/publications/oxfams-conceptual-framework-on-womens-economic-empowerment$\underline{620269}$

2 lbid., p.19.

${ }^{3}$ The project is funded by the Swedish International Development Cooperation Agency (SIDA) and Danida (Denmark's development cooperation).

4 ARIJ, The Applied Research Institute of Jerusalem, Deir Ballut village profile,

http://vprofile.arij.org/salfit/pdfs/vprofile/Deir\%20Ballut_tp_en.pdf

5 A dunum is a unit of land measuring 1,000 square metres.

6 Kidder, T., Pionetti, C., Chipfupa, U., and Remme, J. (2016). Participatory Methodology: Rapid Care Analysis. https://policy-practice.oxfam.org.uk/publications/participatory-methodology-rapid-care-analysis-620147 
